\title{
Controlling the Uncontrollable! Danish Citizens' Attitudes Towards the COVID-19 Vaccination Program - a Qualitative Case Study Employing the Lens of Bourdieu's Practice Theory
}

Malene Missel ( $\nabla$ malene.missel@regionh.dk)

the Heart Center, Rigshospitalet, Copenhagen University Hospital

Camilla Bernild

the Heart Center, Rigshospitalet, Copenhagen University Hospital

Ida Elisabeth Højskov

the Heart Center, Rigshospitalet, Copenhagen University Hospital

\section{Selina Berg}

the Heart Center, Rigshospitalet, Copenhagen University Hospital

\section{Research Article}

Keywords: 2019-nCoV, COVID-19, Coronavirus, Vaccination, Qualitative study, Bourdieu

Posted Date: December 22nd, 2021

DOI: https://doi.org/10.21203/rs.3.rs-1166941/v1

License: (c) (1) This work is licensed under a Creative Commons Attribution 4.0 International License.

Read Full License 


\section{Abstract}

Background: Vaccination is an effective choice to stop the COVID-19 pandemic. Vaccine hesitancy may, however, be a threat to global health. What is structuring and at stake regarding citizens' attitudes towards COVID-19 vaccination in a society is not yet well understood. The aim was therefore to assess how the attitudes and beliefs of Danish citizens regarding the offer of a COVID-19 vaccine are expressed to make us wiser as to why people have the attitudes towards the vaccination program that they have.

Methods: The study was designed as a qualitative case study including 25 citizens from different parts of Denmark and with different sociodemographic backgrounds. Data were collected through individual interviews and analyzed and interpreted through the lens of Bourdieu's practice theory; the focus being especially on structures, habitus and capita/ within a health field.

Findings: The findings highlight structures that regulate vaccination attitudes in the individual in which perceptions of being included or excluded in the logic of the state are particularly relevant. The individual's usual social network seemed to have less structuring importance for their attitudes for or against COVID-19 vaccination. Participants' health habitus was challenged by COVID-19 vaccination, and it had an impact on their attitudes whether they considered health, illness, and body as an individual or collective responsibility. The collection of health capital and positioning in relation to COVID-19 vaccination attitudes was essential, for which, however, unequal dispositions and conditions for the acquisition of knowledge were decisive.

Conclusions: A belief in vaccination as a way out of the pandemic is seen in citizens who share the basic truth of the state, while holding attitudes against vaccination excludes individuals from community and society. Vaccination is for some citizens of no meaning, and they perceive receiving a vaccination as being made sick, while others highlight a collective responsibility to get vaccinated. Those who have the relevant capital, in the form of expert opinions and knowledge from highly educated people in their close social network, receive support from a collective capital, while other citizens might lack the right to express and act in relation to different approaches to knowledge.

\section{Introduction}

"We can end the tragedy of COVID-19 by stopping the deaths, by stopping the hospitalizations, and vaccines give us the power to do so" was stated by the World Health Organization on the organization's Linkedln page in April 2021. Vaccination constitutes a major advance in the prevention of infectious diseases and is an effective choice to stop disease outbreaks, including the COVID-19 pandemic (1). Research however suggests that the novelty of the COVID-19 disease may lead to individuals displaying indicating a hesitancy to get vaccinated $(1,2)$, which may be a threat to global health (3). Our study is one of the first attempts to determine the attitudes of individuals towards COVID-19 vaccination. While being a Danish-based case study, the research will be representative of this particular phenomenon and 
can inform other countries on what is structuring and thus at stake regarding citizens' attitudes towards COVID-19 vaccination in a society.

\section{Background}

The global COVID-19 pandemic originated in China in December 2019 (4) and has since then spread worldwide with major consequences for communities as well as individual families and people. Several countries have been locked down since the COVID-19 pandemic emerged (5), healthcare system capacity has been overloaded (6-9), economic upheaval (10) and significant mental health issues (11-16) have been reported and more than 5 million deaths globally up until December 2021 have been registered (17). An efficacious vaccine is considered essential to prevent further morbidity and mortality and may therefore prove the long-awaited way effort to end this global pandemic $(18,19)$. Vaccines are thus important public health interventions and recently vaccines against COVID-19 were approved worldwide; to date 135 candidate COVID-19 vaccines are in clinical development and 194 are in preclinical development, using a range of vaccine platforms (20).

Although long-term control of the COVID-19 pandemic is linked in part to the development and uptake of a preventive vaccine, there is a segment of the population internationally that refuses or is hesitant to get vaccinated (2). Vaccine hesitancy can be defined as "delay in acceptance or refusal of vaccines despite availability of vaccination services" (3), and history shows that vaccine hesitancy and negative opinions regarding vaccination have existed on a global scale as long as vaccines have (21). The mandatory vaccination of smallpox in Britain in the 19th century led to the establishment of an anti-vaccination league (21) and up through the 2000s, claims that the MMR vaccine brought about autism in children which yet again led to a rise in the anti-vaccination movement with an epidemics of measles (22). Most recently, the HPV vaccine led to an increase in vaccine hesitancy in Denmark (23), when several reports of severe side effects emerged. This meant that several refused the HPV vaccine even though there was no evidence behind the reports (24). An association between not getting the HPV vaccine and not getting the second MMR vaccine was found (23), suggesting an increase in general vaccine hesitancy in Denmark following the enrollment of the HPV vaccine in the Danish vaccination program.

Despite this recent increase in vaccine hesitancy in Denmark, data as of December 7, 2021 show that $78 \%$ of the total Danish population have started vaccination against COVID-19 and $76 \%$ are fully vaccinated (25). The effect of the vaccination effort is now clearly seen on the number of new cases of infection among vaccinated groups as well as on the hospitalization figures, where the proportion of patients over the age of 80 who have been admitted with a positive test for COVID-19 has decreased significantly since late January (26). The healthcare system in Denmark is at the very top among the Danish population when it comes to trust $(27,28)$, and it is reported that Danes are more willing than other nationalities to get vaccinated compared to Swedes, French, Germans, Italians, English, Hungarians and Americans (29); nonetheless, COVID-19 vaccine hesitancy and vaccine uncertainty are being discussed to a great extent by the Danish public. With the Danish background of a population in a western high-income country with high levels of education and current great confidence in the healthcare 
system and the COVID-19 vaccine program, it is interesting that there are still people in this population who are skeptical or even dismissive of vaccination in the middle of a prolonged pandemic.

Comprehensive understanding of Danish citizens' attitudes towards the COVID-19 vaccination program might thus function as a case to learn from.

It is described in research that reasons for vaccine hesitancy are many and have been linked to various demographic factors such as being female, lower age $(<65)$, of a lower socioeconomic position and geographical location $(22,24,30)$. Vaccine hesitancy is also associated with personal factors such as psychosocial determinants, health beliefs, personal experience with the healthcare system, preference for alternative medicine and general distrust in authorities $(2,3,30,31)$. Furthermore, attitudes toward receiving the vaccine are heavily dependent on the sense that those around the individual, who they respect, are also taking the vaccine themselves (32). This suggests that the individual's social circle is influential when individuals contemplate whether to get the vaccine, showing a social component of vaccine hesitancy. While newly introduced vaccines have always been surrounded by skepticism from the public, it is difficult to compare the COVID-19 vaccine with former vaccine hesitancy, because the global health threat, economic challenges, and community lockdowns caused by the pandemic as well as the newer technology of mRNA-based vaccines (33) and the very rapid development of the vaccine itself might affect public attitudes and decisions in ways we are not aware of. Therefore, public attitudes towards the COVID-19 vaccine are particularly interesting to examine in-depth with the Danish population as the case example.

As shown above, previous vaccine hesitancy research highlights that the vaccination behaviors of the individual's social networks are a predictor of own behaviors $(34,35)$, so it is clear that our social milieu affects our vaccine decisions. Missing from the literature is however a theoretical account of how and why this is so; how the beliefs of vaccine-hesitant or -rejecting citizens, but also those who accept vaccinations, are socially constructed, acquired and reinforced. This paper draws on Bourdieu's notions of structure, habitus and capital to elaborate these perspectives. Therefore, the present study aimed to assess how the attitudes and beliefs of Danish citizens regarding the offer of a COVID-19 vaccine from the Danish healthcare system are expressed in order to make us wiser as to why people have the attitudes toward the vaccination program that they have.

\section{Methods}

\section{Design}

This study was designed as a qualitative case study, which is considered particularly well-suited for extensive and in-depth descriptions of complex social phenomena (36). The study employed a methodology that emphasizes an open listening position to social discourse. The study was guided by the theory of constructivist structuralism and the concept of sociology of action from the theoretical lens proposed by Bourdieu and his practice theory; the focus being especially on structures, habitus and capita/ within a health field $(37,38)$. This methodology supported us to construct categories of analysis 
that could account for the existing social discourse. A Bourdieu-inspired approach offers a theoretically interesting and empirically fruitful perspective on the study of individuals' attitudes. Bourdieu's epistemology transcends dichotomies in the social sciences - between objectivism and subjectivism, as he collectively describes them (39). That is, Bourdieu at the same time incorporates both objective material conditions such as the distribution of money and titles, and subjective conditions such as individuals' experiences, perceptions, and habits. This enables Bourdieu to point out a concordance between social and mental structures. Since we want to understand the relationship between individuals' placement in social and societal structures and their attitudes towards COVID-19 vaccination, there is a need for precisely such an integration of these two perspectives. According to Bourdieu, the fact that the object of analysis is constructed from the beginning means that it is not given in advance which attitudes or interests are linked to different social positions. In addition, Bourdieu perceives the social world as relational and not substantially constituted (40). Social identity is defined and defended through differences, and because differences are recognized as social differences, they are perceived as value differences. In relation to the study of attitudes towards COVID-19 vaccination, it follows that an individual's attitudes cannot be understood separately from what others believe.

In the present study, our work is based on health as a constructed and structured field. In the field of health there is a wide range of institutions, such as the National Board of Health (authority), the World Health Organization (WHO), as well as knowledge producers such as universities and research institutions and institutions that develop knowledge that is relevant to the production of vaccines. Dominant positions are also held by the pharmaceutical industry and institutions within the EU (38). In the field of health, one thus sees both public and private stakeholders as well as hierarchies and contradictions between evidence-based and experience-based knowledge and between scientific and alternative knowledge. In addition, it can be said that there is a kind of doxa (implicit rules in the field) in the area of whether one should receive a COVID-19 vaccination in order to keep the body healthy and free from disease as COVID-19. For Bourdieu, the state is always active, although we often do not think about it (41). On March 12, 2020, however, we in Denmark and internationally experienced direct and clear effects of the state acting as a meta-power field. Quarantine, border closure and closure of institutions are examples where one can register the direct effect of the power of the state and its combination of symbolic and secular power (42). The COVID-19 pandemic thus caused all the capitals of state power to be activated when the population needed to be informed about the disease and the policy measures taken in response to it.

\section{Participants and recruitment}

With the objective of collecting the greatest possible amount of information on Danish citizens' attitudes to COVID-19 vaccination, a strategic selection of cases was found to be most appropriate (43). Both typical and average cases (i.e. individuals who were positive towards vaccination) and atypical and extreme cases (i.e. individuals who were skeptical or opposed to vaccination) were included in the study. Participants were also selected based on sociodemographic characteristics such as gender, age, education level and whether they lived in major cities or rural areas in Denmark. Participants were 
recruited through posters, social media and snowballing (44) by encouraging Danish citizens to approach the research team via phone or e-mail if they were willing to attend an interview about their attitudes towards COVID-19 vaccination. Information about the study was e-mailed to those citizens who showed an interest in the study along with an informed consent form. Interviews were conducted in March to April 2021. Data as of April 26, 2021 show that $21 \%$ of the total Danish population had started vaccination against COVID-19 and 10\% were fully vaccinated at that time. That is, one-tenth of the Danish population had gained almost full immunity to COVID-19. Participant characteristics are presented in Table 1. 
Table 1

Characteristics of participants

\begin{tabular}{|c|c|}
\hline & $\mathrm{N}=\mathbf{2 5}$ \\
\hline \multicolumn{2}{|l|}{ Age, years } \\
\hline Mean (SD) & 54 \\
\hline Range & $22-75$ \\
\hline Male & 11 \\
\hline Female & 14 \\
\hline \multicolumn{2}{|l|}{ Marital status } \\
\hline Married, cohabiting, or in a relationship & 12 \\
\hline Living alone & 13 \\
\hline \multicolumn{2}{|l|}{ Education } \\
\hline Primary school or less & 3 \\
\hline Further education (<3 years) & 6 \\
\hline Further education (>3 years) & 7 \\
\hline University & 9 \\
\hline Retired & 6 \\
\hline \multicolumn{2}{|l|}{ Region of Denmark } \\
\hline Capital Region & 13 \\
\hline Zealand Region & 7 \\
\hline Southern Denmark & 2 \\
\hline Central Jutland region & 3 \\
\hline Region of Northern Jutland & 0 \\
\hline \multicolumn{2}{|c|}{ Current attitude towards COVID-19 vaccination } \\
\hline For & 15 \\
\hline Against & 10 \\
\hline \multicolumn{2}{|c|}{ Attitudes towards other vaccines (childhood, travel, influenza, HPV) } \\
\hline For & 25 \\
\hline Against & 0 \\
\hline
\end{tabular}




\begin{tabular}{|ll|}
\hline & $\mathbf{N}=\mathbf{2 5}$ \\
\hline Attitudes towards COVID-19 vaccination in the close social circle & \\
For & 14 \\
Against & 3 \\
Different attitudes & 8 \\
Comorbidity & 12 \\
\hline
\end{tabular}

\section{Data collection}

The appropriate number of interviews in case studies depends on the phenomenon under investigation and the scope of the study. It is recommended that anything less than 15 interviews per case study is generally not considered sufficient (36). Data for our study were collected through individual interviews with 25 Danish citizens. Such interviews are guided conversations that are usually one of the most important sources of case study evidence (45). With the aim of understanding the social practice that shapes the decision-making process around vaccination, we sought to explore how participants' individual interests related to the interests of their social group. We aimed to examine how these interests reflected their habitus and became sources of capital. In addition to the participants' subjective understanding, another focus of the analysis was on the structures within which the participants acted; i.e. how their social systems were stratified, and how participants were part of these social systems as well as which options this equipped them with related to the COVID-19 vaccination situation. A flexible semi-structured interview guide was applied to understand the perspectives of the participants by focusing the questions and prompting for more information when something interesting or novel emerged (44). The interview guide is presented in Table 2. 


\section{Background information}

Gender

Age

Comorbidity

Job

Education

\section{For or against COVID-19 vaccination}

If you got the offer of a COVID-19 vaccine today, would you answer yes or no? / Why did you say yes or no when you were offered a vaccine?

What are your considerations in relation to saying yes or no to a COVID-19 vaccination?

Have your decision or considerations with respect to the COVID-19 vaccine changed over time?

Could your decision or considerations change over time? Can you elaborate on that?

\section{Personal experiences with other vaccinations}

What experiences have you had with previous vaccines that you have received?

What thoughts do you have about side effects and the like of the COVID-19 vaccine? Do you know anyone who has experienced side-effects? Can you elaborate on that?

What are your thoughts on the COVID-19 vaccine compared to other vaccines?

If yes to COVID-19 vaccination: What health benefits / disadvantages do you see from getting the vaccine?

If no to COVID-19 vaccination: What health benefits / disadvantages do you see from not being vaccinated?

Do you have children? If yes, did they follow the childhood vaccination program?

\section{Social network}

What are the attitudes of your closest friends and family to the COVID-19 vaccine?

How do their attitudes affect you?

\section{Social media and news}

How do you usually update yourself on news?

How do you keep yourself updated regarding information about COVID-19 and the vaccination?

Do you use social media?

\section{Political handling of the pandemic}




\section{Background information}

What is your experience of the Danish authorities' handling of the COVID-19 pandemic?

What is your experience of the COVID-19 vaccination strategy?

All interviews were conducted by telephone based on ethical accountability to not contribute to the spread of the virus. Four experienced qualitative researchers performed the interviews. The interviews lasted on average 25 minutes (range: 11-50 minutes) and were recorded and transcribed verbatim.

\section{Data analysis}

Qualitative case study research aims at analytical generalization and involves the extraction of abstract concepts from the unit of analysis (45). These abstract concepts are in the present study linked to the theoretical foundations of Bourdieu's structure, habitus and capita/ with the aim to be potentially applicable to other cases. As such, our analytical generalizations use the previously developed practice theory, with which our empirical case study results are related and compared (46). Cross-case analysis and comparisons were thus performed while we nevertheless remained open to revising our theoretical preconceptions based on the actual findings $(36,45)$. We furthermore drew on hermeneutic interpretations by iteratively changing focus between the whole and its parts $(36,47)$. Such interpretations are rooted in semiotics, a field of study that deals with the relationships between representations, intended meanings, and interpretations of signs and symbols. During the analysis, the research team met and discussed the interview transcripts. Data was broken up into manageable pieces, which the research team then reconstructed to reflect back a view of reality. The initial step involved reading the interview transcripts, which led to the development of preliminary notes and memos that were then used to formulate initial categories, themes and relationships. The interpretation of patterns found in the data was the next step and themes were constructed during this process.

\section{The objective moment of the analysis}

The health field for attitudes toward vaccination includes all individuals who relate to COVID-19 and vaccination by taking a stand. With this broad demarcation, the field basically covers the entire social space, with the exception of a probably very small group that does not relate to vaccination at all. Since the boundaries of the attitude field correspond to the social space, the overall field of power is included as part of the attitude field, where it is dominant in relation to attitudes. The state is considered by Bourdieu as such a field of power that possesses a meta-capital that can control and regulate other types of capital $(38,48)$. The capital of the participants is of great importance for their position within the field. There are different forms of capital, each reflecting a form of resource in the individual; both material and symbolic resources. Within the health field, however, these capitals are exposed to the state's ideals of COVID-19 vaccination, and the state thus has a structuring effect on the participants' collection of capital and their positioning in relation to COVID-19 and vaccination. 


\section{The subjective moment of the analysis}

Central to the analysis of individuals' attitudes is also the concept of habitus. It is the habitus of the individual that, according to Bourdieu, determines how they perceive and judge the social world and act in it - including forming attitudes and expressing them $(37,40)$. Habitus is closely linked to the objective position of the individual in the social space, and is created by the possibilities and limitations that this position provides. Habitus is thus the link that connects the objective structures in the field on the one hand, and on the other hand, how individuals relate to these. Habitus must be understood as a system of lasting and changeable dispositions that serves as a framework for the way in which the individual experiences, thinks and acts. It is precisely because habitus is the link between the objective structures (habitus as structured structure) and subjective structures (habitus as structuring structure), i.e. perception matrices and assessment criteria, that both aspects of the analysis are interesting for the study of attitudes.

\section{Ethical considerations}

The study was undertaken in accordance with the guidelines of the Danish Ethical Research Committee and was approved by the Danish Data Protection Agency (P-2020-276). The investigation conforms with the principles outlined in the Declaration of Helsinki (49). The participants received written information about the purpose of the study and their right to withdraw at any time. Written informed consent was obtained from each of the participants before the interviews. Data were anonymized by means of identification codes. The participants were informed that interview data would be treated confidentially.

\section{Findings}

Perspectives on how the attitudes and beliefs of Danish citizens regarding the offer of a COVID-19 vaccine from the Danish healthcare system are expressed and further why people have the attitudes to the vaccination program they have are illuminated in the following three theoretically informed themes (46). Overall, attitudes towards vaccination are seen for and against, which do not always determine what the participants ultimately choose. Thus, in the analysis it was not possible to completely divide the participants into either for or against vaccination, and the presentation below therefore try to describe, and nuance attitudes and considerations more fluently and thus intertwined.

\section{Structures at a macro and meso level that regulate vaccination attitudes in the individual}

- to be included or excluded in the logic of the state and unspoken expectations and obligations in social groups

For Bourdieu the concept of social structure refers to social forces and pathways which are external, relatively autonomous from and more than the sum of individuals (50). This notion of social structure goes beyond descriptions of people's rationalities and social experiences, and thereby enables us to deepen our understanding of those dimensions of vaccine attitudes and beliefs that are out of the 
individual's control and everyday awareness. Structures that affect the participants' attitudes and choices in relation to COVID-19 vaccination are elucidated in the following.

The overall structures of society at a macro level which have an impact on citizens' attitudes towards vaccination concern vaccines as 'voluntary coercion'; disease as a force of nature; and the development and economic costs of the vaccine. Vaccination as 'voluntary coercion' is about how it can be experienced as discriminatory for the individual if it is necessary to be vaccinated in order to participate in ordinary social life. It is perceived as not being fair, but one may feel compelled to do it nonetheless.

It's reminiscent of forced vaccination, and it crosses the line for me. I'm off. I can see that it would boost the economy, and I can see that it will be an advantage for a lot of people who have been vaccinated, but there must be a cat flap for those who do not want to be vaccinated. I do not like that they have to decide, and I think there must be room for both those who cannot and those who do not want to be vaccinated. It is not fair this way (2).

This highlight how perceptions of how the state that decides who should have a place in society, understood in such a way that there will be no place in society for those individuals who will not accept to be vaccinated. With Bourdieu, the state can be understood as a meta-power field that determines the rules of the game in society $(38,39,41)$. Such a meta-power field has its own logics, which can be difficult for outsiders to understand. This means that as an individual in the state you can feel included or excluded depending on whether there is a correlation between the individual's and the state's dominant understandings and logics regarding COVID-19 vaccination or the opposite, whereby the experience of 'voluntary coercion' permeates the individual. As a result, it can be difficult to discuss vaccination with other people if you do not want to be vaccinated yourself, as most Danes are proponents of vaccination and thus (unconsciously) included in the logic of the state (37). Therefore, it can be difficult to go against the public mood, and in this context one can feel stigmatized or ashamed and be called a conspiracy theorist or other negative expressions.

It is as if people are being shamed if one does not follow the herd. At least that is my opinion. It is not easy to think of anything other than the $80 \%$ of the population, and one may well be a little stigmatized or categorized as selfish, or one who does not care about others, or an anti-vaxxer or conspiracy theorist or other negative expressions (25).

Thus, it can be seen how objective structures have subjective consequences (41). It is experienced in this context that society lacks an understanding of people's different opinions, and it is questioned who has the power and right to be critical and say no. Thus, it is easier to discuss vaccine attitudes with someone with whom one agrees. Bourdieu emphasizes that such generally accepted (power) structures must be revealed so that there is an awareness that these conditions are not natural $(39,50)$. Bourdieu's critical errand is thus to show that thoughts, attitudes, and actions that go against prevailing dominant structures must be possible so that there is not just one universal, true, and right attitude toward vaccination. If this is not possible, symbolic violence, as said by Bourdieu, will be the consequence (38, 42), which was also expressed by the participants in relation to vaccine passports, which for those 
individuals who do not want vaccination, can contribute to a feeling of the population being divided into an $A$ and $B$ team. As a citizen, it can feel as if you have lost your free will, or that you as a citizen do not have equal rights and equal conditions, as you are excluded on the basis of a different attitude. This can mean that the individual feels pressured or forced to be vaccinated. What happens in this context can with Bourdieu be explained as that the participants who have a skeptical attitude to vaccination, perceive and assess the world around them (including their own body) with the criteria produced by and reflecting the current dominance conditions $(42,51)$. Thus, participants 'read' themselves through criteria that say that vaccination against COVID-19 is a must, which is contrary to the way these participants understand the world subjectively. This contributes to a controversy over what criteria should be applied to the world and thus how to assess the priority and importance of vaccination.

For others, getting the population vaccinated may be seen as the only way out of the COVID-19 crisis, socially, economically, and mentally, and to return to normalcy. Returning to normal everyday life without the coronavirus and with hugs and closeness can be considered a joint effort that we as a population and a society must make together.

There are two aspects, I think, and one is that you yourself gain greater immunity, and then I also think that it is a form of civic duty. As a citizen, you have to say "okay, this is what we have to live with," so that society can function normally again. It does not help that people, because of some concern, say that I do not want to be part of it. That is not how it works in society in a proper and sensible way. You cannot defend not being vaccinated, because then you can help spread the infection. So, one simply must back this up (13).

These participants are from a Bourdieu perspective together about a basic truth that is not necessarily formulated or expressed linguistically, but which makes the participants' choices and actions meaningful $(50,51)$. This basic truth about COVID-19 vaccination as a way out of the pandemic with its restrictive restrictions is formed by external structures, where the state as a meta-power field is an important player in the way citizens gets their perceptions synchronized (52). If, on the other hand, you say no to vaccination, then it can be seen as shutting yourself out of the community and society. Getting vaccinated is even perceived as a societal duty by some yes-sayers, which is why it is not possible to let one's own worries take precedence, as quoted above. As citizens, we have a common responsibility to move forward and make society function normally again, and for that to happen we as citizens are dependent on each other. In this view, one cannot defend not being vaccinated, as vaccination is about taking care of each other. Being part of the community and being vaccinated for the sake of society and in order to help each other does not necessarily mean that you as an individual are not worried about being vaccinated. In this way, vaccination is regarded as a civic duty and as a public interest and thus as an attitude that extends beyond oneself.

Furthermore, the individual's attitude of not wanting to be vaccinated may have been shaped by a basic attitude that the forces of nature, such as the coronavirus, cannot be controlled by humans, even with a vaccine. Just like weather disasters, viruses occur from time to time, and as there will always be such 
predetermined phenomena that one as a human being has to cope with, there is no reason to fight against them. It can also be seen as the world's way of sorting out the weakest, as there are still too many people on earth. That professionals and the state still recommend vaccination against COVID-19 can be seen as propaganda.

The reason for a hurricane or an earthquake or an epidemic is simply because we are too many people on this planet. And it's the globe's way of dealing with the fact that we're too many people, so we simply must clear out some of us. And one can say, it might go beyond the weakest in society because they do not have an immune system that can cope with an epidemic. I think all this vaccination crap is pure propaganda (1).

According to Bourdieu, the perceived one-sided information which is disseminated by the state, its institutions and professions, reflects current dominance conditions, which can be perceived as an assault $(41,42)$. In this context, it is a question of individuals with a basic assumption of letting the forces of nature determine, may perceive vaccination as a veiled common interest and thus a calculating act. For precisely these participants, herd immunity also comes into play by letting infection spread as a natural approach to get through the pandemic and, best of all, subsequently, which is considered a selfless act that should serve everyone best. For the individuals who hold this conviction, great annoyance is expressed that it does not seem to be an option in the plans made for epidemic control in Denmark, where it is felt that the state has a pervasive narrative that as many citizens as possible should be vaccinated without alternatives. In continuation of this, a question arises regarding who are the right people to judge whether the vaccines are the best option for citizens, and whether one can trust that the state wants the best for its citizens. Following Bourdieu, this can be seen as a dispute over who neglects his own interests by letting them give way to public interests; on the one hand, the participants' norm and assumptions can be considered as a common service that promotes universal interests, while on the other hand it can also reflect a striving to realize a self-interest disguised as a common interest $(42,52)$.

The vaccine's rapid development and financial costs are highlighted but viewed differently depending on whether one trusts one's own, local health authorities and the state as a whole. Experiences that the state has handled the COVID-19 situation well contribute to a feeling of being well taken care of as an individual and as a citizen, and that one is able to feel safe. It also means that you as a citizen have confidence in the pandemic-related information, including on vaccination and the development of this, that you receive. In addition, a basic confidence is expressed that in Denmark the state would not start vaccinating the population if the vaccine were not safe.

I assume they [the health authorities] know what they are doing. They do not send out millions of vaccines and kill half the population. I trust that of course they have done it properly and checked what they need to. I have a belief that there are some people who are smarter than me who have seen the vaccines through and who have said that they are safe enough, and I myself have no reason to doubt that. I have faith in experts, and I have confidence that especially the Danish experts are the ones we can trust (15). 
According to Bourdieu, trust is a type of symbolic power $(37,39)$. Symbolic power is the power to construct reality and the power to make people see and understand the world in a certain way; it is an invisible power that can make a given understanding of reality appear inevitable and true, without it being clear to those involved that it is an exercise of power. The understandings of reality that result from symbolic power are embedded in habitus and become part of society's doxa $(38,50)$. The exercise of symbolic power is formalized in what Bourdieu calls 'pedagogical action', that is, all 'authorized' forms of teaching or information about how the world is organized (53). In the context of participants' attitudes towards vaccination against COVID-19, trust in the state rests on general values such as health, justice, credibility, morality and responsibility in a system based on knowledge and expertise that goes beyond individuals' own immediate experiences. Contrary to this bridge-building trust between state and citizen, however, our analyses also show a limited trust among some participants, where it is experienced that the state is constantly trying to define the norms for epidemic control in society. In this context, communication - the 'pedagogical action' - from the state is perceived as harsh, direct and patronizing, in which the state tries to intimidate the population. It can be experienced as if the state appeals to the fears of the population by using daily infection rates and other fear rhetoric. This can lead to a lack of or limited trust in the state and thus in the vaccine strategy. For some, the rapid development of vaccines may also arouse suspicion that the decision to vaccinate citizens is not well thought out and is rooted in a financial incentive. A lot of money has been spent on the development and purchase of vaccines, but as a citizen it can be questioned whether the prioritization of COVID-19 vaccines is defendable in relation to treatment against other diseases such as cancer.

To me, this vaccine seems like a political decision. We need to be scared, but then we can get vaccinated. Try to consider all the money that has been pushed into this [vaccine]. Imagine if you had spent it on cancer instead. There's so much danger out there. And all the fear rhetoric; that we have been bombarded daily with infection rates... There has been a lack of relativism and proportions. And then I feel that we are being talked down to. We're not stupid. But I think it's a little hard and patronizing (14).

The state as a meta-power field is described by Bourdieu as a field with a maximum of autonomy (38, 39), which through grants can purchase vaccines that can control and regulate the health of citizens. Thus, it is seen how the state has the power to define what is healthy and how the health of citizens must be developed and supported. According to Bourdieu, the degree of this centralization of power has implications for social order $(48,50)$, that is, the system that structures participants' attitudes and actions toward COVID-19 vaccination. In this context, the doxa of the state is about COVID-19 vaccination being carried out to protect citizens and public health, but at the same time these obvious claims are challenged by citizens for whom vaccination and health are not necessarily coherent or who distrust the motive for vaccination. In addition, an ethical question is raised in relation to the new technology for the development of vaccines, where it is experienced by some participants that the limits of what one can do are expanded. The concerns about a new technology may be that we do not yet know the future prospects and possible consequences, which in itself may seem daunting to the individual citizen. 
At the meso level, the external, autonomous structures are about how the participants' family and other social networks structure and shape their attitude towards vaccination. Society's social distancing restrictions mean that in families or other social circles one cannot be together as one could before the coronavirus pandemic; the risk of infection lies in the minds of many, and it means something for habitual human relationships and interactions. Therefore, there may be a pronounced desire for us to be vaccinated; both in the family and other social contexts in society, and unity and community thus become of great importance. However, it is seen that families can also have unspoken expectations as to whether the family in question should say yes or no to vaccination. Thereby, the individual can feel obligated to follow their family's wishes, without vaccination or expectations being explicitly discussed. Such expectations can also be expressed in other social groups of which the individual is part.

I am in a group with those who have my disease, where the doctors had recommended us for vaccination. And there was a widespread attitude in the group that one should have the vaccine. It was so implicit, because then one does not have to worry so much anymore (3).

These unspoken expectations can be explained with Bourdieu by the fact that individuals often act without being explicitly rational and by not constantly consciously planning their behavior (50). There are also families where one seems to be able to agree that the disease is not dangerous and that it therefore seems excessive to have to be vaccinated, while other social groups may share a desire not to be vaccinated but to be infected with coronavirus instead. In these groups, what Bourdieu calls heterodox input $(38,40)$ is produced in the vaccine perception. This is done through theories or ways of thinking about the body other than the biomedical and in the conventional medical examination designs from clinically controlled studies and cohort studies, which is typically the knowledge from which the health authorities obtain evidence for their recommendations and directions for public health, including vaccination (38). In several families and other social circles, however, there may be divergent attitudes as to whether one should be vaccinated or not, and it is thus not always the case that one can get support for one's attitude from the usual networks. COVID-19 vaccination thus challenges the participants' habitus and tendency to think and act in certain ways, which can also challenge their position in the social space. Expectations of what attitude to vaccination one should have in a given group can thus be perceived as either binding or supportive; they can be shaped by family and social networks or they can be different. This is inconsistent with Bourdieu's theory that individuals are primarily structured on the basis of a perception matrix, which is shaped by the individual's conditions of upbringing and history (39, $41,50)$.

\section{Health habitus is challenged by COVID-19 vaccination}

- health, illness and body as an individual or collective responsibility

Habitus is about some learned dispositions that make you as an individual act in certain ways, but without being explicitly rational about it $(39,42)$. The individual is thus first and foremost a body shaped by a context and a story. The body is born somewhere, by someone and under certain social conditions, which are embodied and incorporated as a matrix and become a program for how to behave. Habitus is 
structured by objective conditions of upbringing and principles, which are acquired in a family, but habitus also undergoes continuous transformation (38). Habitus is thus understood as a system of lasting and changeable dispositions that serves as a framework for the way in which the individual experiences, thinks and acts. The theme illustrates health and illness seen as either an individual or collective responsibility as well as the connection between the individual's attitude to illness, health, and vaccines (and medicine) in general and their attitude toward the COVID-19 vaccine in particular. Below is a description of the psychological and social conditions that may be important, as attitudes, perception and action patterns will be influenced by habitus.

The belief of many of the participants is that if you just live a healthy life, then you have a good immune system, and then you do not get sick. For people who subscribe to this attitude towards health and disease, at the individual level, there is nothing rational about vaccination. This attitude focuses on 'the strong body' and maintains that this body is the individual's own responsibility as a basic precondition. The individual's own efforts to keep the body in good physical condition with exercise and a healthy diet are highlighted as important in order to be able to opt out of vaccination. In addition, there is a belief that if you are healthy and well, then you can tolerate getting COVID-19. There is also an internalized belief at the individual level that the body should be treated 'naturally', and one as an individual may therefore be reluctant to take modern medicine and may disagree with the idea that an artificially produced vaccine should be injected into the natural body. The body must cope in a natural way.

Basically, I think we can tolerate getting sick, because we are born with a well-developed immune system. I think one should eat a much healthier diet and vitamin D and more outdoor life and stuff like that. I'm physically active, so I'm not afraid of getting corona and I believe that the body can handle it itself; medicine is an artificial thing that you get put into the body. With the corona vaccine, I feel sickened as a completely healthy young man with a well-functioning immune system - I am not vaccinated against colds either (8).

In addition to socialization to and in social positions through habitus, citizens are also, according to Bourdieu, shaped by the state $(52,53)$. The dominant construction in relation to the body is what can be called the 'state-authorized' healthy body, from which citizens know that the body must be active and maintain a healthy diet and a good sleep pattern if it is to live long and well (38). With Bourdieu, the stateauthorized body is communicated both through good advice and instructions; in other words, pedagogy coupled with guilt, moralization, and individualization (53). Thus, it is a moral problem not to live up to the ideals, and the individual bears the responsibility for his or her own health, as expressed by the participants. In the context of COVID-19 vaccination, however, there is a paradox in that the participants on the one hand are controlled by the state at a distance and assess their own body and health based on the dominant healthy body that has been mediated by the state. But on the other hand, several of the participants describe their own health assessment when it comes to vaccination against COVID-19, where they deviate from the state doxa and emphasize their own control over their body and their belief that vaccination will not optimize the body's defenses - perhaps even the opposite. 
For the participants who want to be vaccinated, from a 'micro level' perspective, this preference is about wanting to protect themselves and take care of themselves. Age can be important in this context, as it is understood that the elderly are expected to become the most ill with coronavirus. In addition, the belief that you are not in a risk group can, on the contrary, legitimize the belief that you should opt out of vaccination. Based on one's own belief, the vaccine might also be seen as a way out of lockdown and restrictions, which can be experienced as a deprivation of liberty; by being vaccinated you can get together with family and friends and live a long-missed everyday life again. A strategy for the individual who chooses to avoid vaccination may be to choose to prioritize activities which do not require vaccination, such as reading books. For some people, it is not so important at the individual level to have society re-opened if it requires vaccination. You might also feel that if your own social distancing measures and hygiene precautions are within current guidelines, then there is no threat of becoming infected and thus it can be considered fine for you to opt out of vaccination.

If you focus on everything you do not get, then it is clear that then you have to go out and be vaccinated, so you can quickly get out and get what you think you are missing out on. But I have deliberately chosen to say that then there are some other things; I have read a lot of books, I have not had time otherwise, and then I may not have come to the theater, etc. But I will not be vaccinated to be able to go to restaurants (19).

According to Bourdieu, as an individual one incorporates a perception of the world as it appears from one's position, which gives rise to different ways of perceiving, thinking and acting $(37,42)$. In relation to vaccination against COVID-19, several participants are based on this self-position and worldview, and vaccination must therefore have direct relevance to oneself, e.g. in relation to age, risk of illness or participation in social activities. If it does not, and vaccination does not optimize one's own interests, it does not give meaning and value to the individual.

Getting vaccinated prior to the COVID-19 pandemic in connection with travel or the child vaccination program was for many not a reflective decision but something one does without questioning it. Here habitus becomes a clear expression of the individual's unconsciously learned dispositions to act in certain ways $(39,42)$. The call and recommendation for COVID-19 vaccination, however, shifts from this approach, and one suddenly begins to take a stand. This means that many people who were not previously skeptical about vaccinations are actively beginning to consider whether they want to be vaccinated or not. It is primarily a matter of the COVID-19 vaccines being developed with new technology, but this stance can also stem from the individual's perception of themselves as not being at risk from COVID-19 disease as they are a younger person with a good immune system. This shows how the COVID19 vaccines challenges the participants' habitus and disrupts the framework within which they experience, think and act. According to Bourdieu, the individual is limited in possibilities of action and influence by virtue of the social structures that determine the actions of the individual $(39,50)$. However, it can be seen how the participants in relation to COVID-19 vaccination act significantly differently and more reflexively than expected. Although they might have been given vaccinations in the past, for some participants there may be uncertainty associated with the COVID-19 vaccine, which can be viewed as an 
experiment conducted with humans. Underlying this attitude can be found, among other things, a belief that we as humans are basically born with a well-functioning immune system, and that we can therefore well tolerate getting sick. Medicine and vaccinations are therefore quick-fix solutions to inappropriate and unhealthy approaches to our lifestyle.

Basically, I think we can tolerate getting sick, because we are born with a well-developed immune system. So, for me, both medicating and vaccinating have become quick-fix solutions; so, we can live a bad and unhealthy life and then we can just be repaired with medicine. It's kind of the mindset we live with. And it's a paradigm I wish we would get away from and then instead have more emphasis on ecology and vegetables (23).

Thus, there is a discrepancy between the participants' habitual and incorporated actions on the one hand, where one previously got vaccinated without being explicitly rational about it, while COVID-19 vaccination on the other hand brings the embodied health messages with the body's efforts to perform and optimize to the fore. For those participants who do not want to get a COVID-19 vaccination, it is the stateauthorized healthy body that generates and structures vaccination notions and practices. In connection with this, the interviews show that you can be a supporter of vaccines against diseases that you feel threatened by, but if you do not feel threatened by coronavirus and have a perception that you will not get sick from it, then COVID-19 vaccination is perceived as unnecessary. A correlation between saying no to COVID-19 vaccination and an attitude of not wanting to take medication at all or an insecurity about using other medications is also clearly expressed. It is thus seen how habitus can be changed by new knowledge and new experiences, but also how attitudes toward the new COVID-19 vaccination are formed from previous attitudes. In contrast, experience of previous vaccinations that have been unproblematic and without side effects may mean that one is not uncertain or worried about the COVID-19 vaccine. Receiving the vaccine to protect oneself, as when one has previously received other vaccines, is thus also highlighted. That is, with Bourdieu $(39,42)$ saying that when these participants act on past experiences and perceptions, they rate COVID-19 vaccination as something that makes sense and value.

For several participants, the vaccine can help to create security both for oneself but also for others. This means, among other things, that you may be afraid of getting COVID-19 and are not willing to take that risk, and thus vaccination becomes an important way of protecting your health. Knowledge about the course of COVID-19 disease thus makes it easy to see the benefits of vaccination. There is also a very strong faith in the state's decisions and scientists' investigation of side effects.

I have faith in science, so when we have obviously got a virus that we may have to live with, I believe that they can constantly adapt the vaccine to how the virus develops. If one could avoid such viruses, then that would be best, but I think it's amazing that science can help humanity so that we can survive such situations. I am convinced that there will be some minor side effects; maybe you get a little uncomfortable or get soreness at the vaccination site. But that does not worry me. I have confidence that the vaccines we receive are in order (6). 
As an ordinary citizen, according to Bourdieu, one has incorporated the state into oneself $(38,40)$. The state and state regulation thus have an indirect but great significance for the regulation of the lived life including health and unhealthiness. The state is therefore relevant when individuals orient themselves towards how a healthy body acts, and in relation to COVID-19 vaccination, the state (and science) is granted high trust by these participants. Thus, on the one hand, there is a part of the population that trusts the vaccines, because they trust the state, even though the vaccines have been developed in a hurry, and the side effects are unknown in the long term, and then on the other hand there is a part of the population that thinks that because we do not understand the vaccines well enough, there will be errors. As a citizen, you can be unsure whether you will receive knowledge of such (possible) errors. In addition, there are concerns about the new technology used in the COVID-19 vaccines, which can seem daunting. Some participants also have the perception that one can die from the vaccination or its side effects and therefore dare not get the new dangerous vaccine despite the fact that they have previously been vaccinated against other diseases and that vaccination is therefore an established part of their perception matrix. According to Bourdieu, all individuals have an immediate desire to confirm already existing habitus in order to ensure the stability of habitus, and situations that challenge and question one's habitus will thus be avoided $(37,50)$. Habitus, however, is a system of dispositions, where disposition is meant an inclination to act in certain ways, and such a tendency is more a tendency to do something than a compulsion. Furthermore, habitus always functions in relation to other social contexts, which is why the same habitus can give rise to different actions and attitudes depending on the nature of the social context. In relation to COVID-19 vaccination, this means that even though participants who have previously had other vaccinations internalized in their habitus, the combination of a lack of knowledge about and experience with the new vaccine with consequent insecurity and uncertainty means that one is still reluctant to receive the vaccine. It is also most often the case, according to Bourdieu, that individuals only really discover the perception matrix that is active within them when changes occur (38).

Concerns were also raised about whether the body can become resistant to vaccines if we continue to vaccinate ourselves against everything, and whether in this way vaccination can affect one's immune system in an inappropriate way. There was also uncertainty about whether the vaccines can manipulate one's genes in order to disrupt the normal healthy body. This may also have roots in a perception that medicine is not good at all and that it is artificial for the body, whereas healthy food and exercise would be a better alternative. This shows how previous attitudes and behaviors get confirmed, thereby securing habitus (37). Several participants raised concerns about whether people who have been vaccinated risk giving healthy people autoimmune diseases and injuries, which will be an assault on the individual.

\section{Collection of health capital and positioning oneself towards COVID-19 vaccination}

- the unequal dispositions and conditions for the acquisition of knowledge

According to Bourdieu, a social group is defined relationally in a social space by its possession and utilization of various capitals such as economic, cultural and social capital (48). The concept of health capital is directed more specifically at the differentiated investment of social groups in their own body. 
The intention is to optimize, maintain or reduce the loss of social position in a time when body and health have a strong focus; health capital, however, requires the other capitals $(38,48)$. Health capital is a sociological concept and therefore has nothing to do with 'healthy' and 'unhealthy' in a biomedical sense. What is particularly interesting in relation to health capital and COVID-19 vaccination opinions and attitudes are individuals' preconditions for being able to position themselves, which is oriented according to their cultural rationality in relation to knowledge, research and evidence. These practices highlight that a person has 'done their research' and made what, to them, is the appropriate choice around vaccination. The practices around questioning science and making 'alternative' choices to the mainstream, however, also articulate forms of cultural capital. In the following we present how the participants relate to knowledge in the field of COVID-19 vaccination, including the use of media, news channels and other knowledge information, the participants' critical stance on knowledge, and their ability to assess knowledge.

The participants retrieve COVID-19 information from several different sources. Some inform themselves via daily news updates, which can range from superficial sensational headlines in morning newspapers to more comprehensive articles in major dailies. Participants seek out and select media based on motives that may have to do with meeting needs or based on already established habits. When it comes to information about the coronavirus and COVID-19 vaccination, knowledge is obtained that for some citizens will reflect and confirm their own attitudes, and which can provide cohesion with others, whereas other citizens seek more nuanced knowledge as well as general knowledge, which they believe can expand their own positions. For the latter group, their choice of news media is also about them being tired of the morning press' sensational coverage, which is more about publishing exciting stories than about factual interpretations of the pandemic and vaccination. Several participants also point out that if you want knowledge that is the most credible and without other interests, then the National Board of Health and the National Serum Institute are the best places to get it from. The Internet, including Google, is also considered by both yes and no sayers to be a reliable source of knowledge. The participants thus have different dispositions and conditions for obtaining knowledge about COVID-19 vaccination, but all participants nevertheless want to optimize their own health and reduce the risk of disease.

I update myself on the pandemic [through] TV, radio, newspapers and online from time to time. If I want to go more in-depth, then I go to the National Board of Health and the National Serum Institute, because there I am sure I will get an independent briefing. I want to be sure that what I have grasped is credible (13).

Health capital comes with Bourdieu in play as a differentiated investment in own body $(38,39)$, either by optimizing the body through vaccination against COVID-19 or just the opposite. In general, the hunt for capital can explain much of what individuals do. Gaining knowledge about and taking a stand on vaccination, whether one says yes or no to it, can be seen as a struggle to raise health capital; a deepseated, socialized way of being that is recognized and acknowledged by others $(39,42)$. Health capital and recognition thus refer to a striving to be noticed and give social identity whether society in general allocates this position positive or negative capital. In fact, Bourdieu's general view of man is that it is not 
self-interest that is the primary driving force for human beings, but the desire for recognition from other human beings (42). The de-coding that thus takes place in the acquisition of knowledge, whether the individual's attitude and actions are in favor of or against COVID-19 vaccination, can therefore be translated into recognition and thus capital, if, as Bourdieu points out, there is a 'market' or a social microcosm into which capital can be brought (48). Capital must thus be brought into a social context where it is recognized, ascribed value and thus gives social prestige.

There was also a group of participants for whom Facebook is considered the most reliable source when it comes to 'real' knowledge, as dominant narratives expressed via established news channels can be perceived as inadequate and manipulative. It can be seen that these news channels talk vaccine concerns down, whereas Facebook provides useful links to articles and research that take a more critical view of the entire vaccine strategy and provide alternative solutions to getting out of the pandemic than vaccination. This group of citizens can be said to challenge the doxa in the health field by articulating and challenging the dominant attitude towards vaccination and instituting new criteria or ways of thinking about the body as legitimate rather than the biomedical theory. For most participants, it means something to be 'well prepared' in terms of knowledge and meaning, and where you get your knowledge from, seems to be of great importance. Thus, it can be seen how the chosen news and knowledge media provide a social security in that one belongs to that particular group. In order for capital to create such an affiliation, according to Bourdieu, social agents must exist who, by virtue of their habitus, can recognize the type of capital in question and recognize its value $(40,53)$. Internally, in such environments that challenge the dominant vaccine doxa, a capital that virtually negates the dominant culture thus functions. However, participants' approaches to how outreach they are in relation to knowledge about the coronavirus and vaccination vary. Some choose not to orientate themselves at all, whereas others update themselves daily on infection figures, while others go in and out of the news media, as on the one hand they want to follow news, but on the other hand do not want to be 'infected' by the media's fear scenarios. The COVID-19 pandemic has also meant for some of the participants that they have started following news and knowledge about the current situation, which otherwise would not have been a daily part of their lives. However, there are participants who are clearly critical of the media's portrayal of the pandemic and vaccination and who emphasize that the media focuses exclusively on one dominant and unvarnished narrative that is intended to intimidate the population.

There is one narrative which has become the only right one and which is what the media largely perpetuates. They try to scare people by writing how many have died, etc.; they put up frightening death tolls, but there is a lack of perspective on how many people have committed suicide and how many social costs the shutdown has had. But the media is discouraging so people are scared. Anxiety rises, and it can drive one's immune system down because so many waste products... i.e. negative chemical reactions, enter the body because you are constantly on the run. It may be even worse than the virus itself $(17)$.

This can lead to you as a citizen being frightened and anxious to such an extent that it can be felt in your own body. Part of the criticism of the media coverage and the dominant narrative is also that as a citizen you can feel that the experts and professionals who are against the vaccine are not represented and 
heard in the media. This calls into question who has the power and thus the capital to define and determine the rules of the game or the knowledge that must apply when deciding on vaccination.

The participants' attitudes towards the health authorities' handling of the corona pandemic are oriented along two poles. At one end of the spectrum, there are experiences that the closure of society has been excessive and not fair, and that the health authorities have not communicated logically and clearly and have used explanations and arguments that ordinary people cannot understand. There may also be experiences that the health authorities seem insecure and do not acknowledge their mistakes. At the diametrically opposite pole, a great deal of respect for and trust in the health authorities is emphasized, as well as trust in the knowledge and the decisions they present. There is a belief that choices and decisions are based on expert knowledge and research, and the state is thus seen by these participants as the protector of the citizens. In addition, however, an expectation is also emphasized that it is the health authorities' responsibility to explain to the population what vaccination is about and what there is of safety and uncertainty about it, so that Danes have the opportunity to make decisions on the best possible basis. Furthermore, there is an expectation of the health authorities that they should also provide more information about solidarity and community spirit, and what this means in connection with vaccination.

I also think they [the health authorities] need to say something more about solidarity and what it means for society and for the protection of other people when you get vaccinated. The so-called community spirit must be activated. We have a commitment to each other and to society and the economy (11).

In this context, the state is not only seen as an unchallenged authority, but the expectations are also that the state must protect the citizens both from the stranger, the disease, and also from each other, as it is expressed by Bourdieu $(50,53)$. It is thus not just about information to the individual citizen on an individual level about COVID-19 and vaccination, but it must be clear that we as citizens have an obligation to each other. By everyone taking responsibility, so that vaccination is not something you do just for your own gain, social capital is put into play $(42,48)$.

In order to be able to make a decision about vaccination against COVID-19, you as a citizen may need to familiarize yourself with knowledge about disease and vaccine. Several participants emphasize the importance of having time to think before saying yes or no, and that the time factor helps to create security. Insecurity arises for many from an experience of being ignorant, in combination with the fact that the vaccine is completely new and nothing is known about long-term side effects. What can create security is when you see others being vaccinated. Likewise, it can be reassuring to know a professional in your social circle who says yes to vaccination. It is thus seen that the possibility of assessing the current knowledge, for several of the participants, is connected with their own collection of experience as well as the experience of close 'experts' more than just the information provided by the state. The concept of capital can, with the support of Bourdieu, help to explain people's actions $(38,48)$ and thus shed light on the participants' tendency to lean on their own 'experts' when shaping and constructing attitudes to vaccination. Cultural capital deals with education, knowledge and competencies, while social capital 
refers to the individual's social network and connections (48). Thus, the concept of capital can help to say something about how those who have capital in the form of expert opinions and knowledge from highly educated people in the close social network get support from a collective capital. However, the state as a meta-power field $(38,52)$ is an important player in the way in which the knowledge of these participants is synchronized.

Others experience that even though they have a desire to make a decision about vaccination on an informed basis, the communication from the health authorities is opaque, which makes it difficult to make a choice. They experience that the information about vaccination goes in different directions, which is why the purpose of vaccination is not clear.

I have a mixed feeling towards the Danish health authorities. It is, of course, an unknown situation, but I do not think the communication has been particularly good or explanatory. I'm missing a whole lot of arguments for what they're doing, and the logic is also missing for me. There are no explanations that ordinary people can understand (12).

For many of the participants, knowledge is gleaned from television and the Internet; a one-way flow of information and knowledge which can be frightening, and which can mean that one is skeptical about vaccination. These participants emphasized that ordinary non-scientific information about vaccines and vaccination for the individual citizen would suit them better and provide a better basis for the decision on vaccination. In this way, it could mean that the individual citizen feels involved in the decision and does not just experience being controlled by the state from a distance. According to Bourdieu, the state reproduces inequalities (53). This means that when the state's information about COVID-19 vaccination takes place in the form of one-way communication, the participants who feel off and overwhelmed in relation to information about vaccination will thus be further marginalized on the basis of various social differences, resources and cultural environments.

Some participants also have the experience that the state keeps information and knowledge about the vaccines secret from the population, and that they deliberately publish incorrect numbers and keep people in ignorance. These participants have a desire for full transparency, where all intermediate knowledge is also presented, so that the population has the opportunity to access all the information in order to be able to assess the relevant knowledge in the field.

First of all, there has been withholding of information. Knowledge is power, and if you can keep people in ignorance, then they may be easier to deal with. The health authorities have not explained well enough about the safety or insecurity associated with vaccination (22).

There is thus a desire for you as a citizen to be invited more into the knowledge as well as non-knowledge or uncertainties that the state is aware of. As a counterpoint to this, there is a group of participants who, however, believe that if you have the right education, then all the knowledge you need is available on the National Board of Health and the National Serum Institute's websites, and thus you have the opportunity to make your own calculations; an approach that requires some form of cultural capital in the form of 
education to seek out and assess the knowledge in question. This shows how the state's meta-capital is perceived in different ways, which gives power over other capitals $(42,48)$, and which can thus be said to lead to 'battles' between the different groups' capitals and about the right to the different approaches to knowledge about and attitudes toward COVID-19 vaccination.

\section{Discussion}

In the field of health, the state must ensure that we are each informed or made aware of what is healthy and unhealthy, and part of this is implicitly about what is normal and abnormal; the state is as such controlling the uncontrollable. In this study we have examined the attitudes of Danish citizens regarding the COVID-19 vaccine program; a program that has been rolled out by the Danish health authorities as a dominant ideal in order to control the pandemic (54). Thus, citizens in the society are exposed to governmental ideals about the COVID-19 epidemic control that have a formative effect. Through our study, we can in this context show how such dominant ideals can lead to some citizens' attitudes to vaccination being granted social recognition while other attitudes are shunned. The findings of our study will be discussed and compared with other research in the following section.

The structures that regulate vaccination attitudes in the individual were illuminated in our study at two levels, the macro and meso level respectively. At the macro level the state plays a dominant role in structuring citizens' beliefs, attitudes and actions related to whether COVID-19 vaccination was perceived as good or bad by the citizens. The important thing in this context is whether you as a citizen feel included in or excluded by the logic of the state. It is common for individuals to perceive and evaluate the world around them (including their own body) based on criteria that are produced by and reflect current dominance conditions; that is, the state's view of vaccination as a form of epidemic control. A belief in vaccination as the way out of the pandemic is thus seen in our study in participants who share this basic truth. On the other hand, individuals who hold attitudes that go against vaccination can feel excluded from community and society. There is a sharp division between the two groups. One group might say that the recommendations for vaccination from the state have to do with regulating the health of citizens based on trust, justice, morality and responsibility in a system based on knowledge and expertise, while the other group might perceive the state's defining norms for health and epidemic control as a form of voluntary coercion and veiled common interest. For the latter group, the basic doxa of the state is questionable, which limits or challenges the trust between state and citizen. A Chinese nationwide crosssectional survey about COVID-19 vaccine demand and hesitancy reported that a total of $83.5 \%(95 \% \mathrm{Cl}$ 82.3-84.8) of participants responded yes to COVID-19 vaccine intent, while only $16.5 \%(95 \% \mathrm{Cl} 15.2-$ 17.7) responded no. A key predictor for an intention to take the vaccine was a reported perception that the vaccine decreases one's chances of getting COVID-19 as well as being unconcerned about side effects (55). The suggestions from this study focus on that increasing perception of the benefits of vaccination are essential, which is confirmed by other research on enhanced epidemic control (56-58); studies which additionally focus on the role of the state to start promoting COVID-19 vaccine uptake. The question is, however, if the state can control the uncontrollable vaccine opponents by providing information on the benefits of vaccination. A systematic review of beliefs and attitudes toward and reasons for non- 
vaccination points out that specific reasons may differ, which means that specific approaches are needed and not general ones if attitudes are to be changed (58).

At the structural meso level, attitudes towards vaccination were in our study expressed as either an unspoken support or as an obligation within the individual's social circle, which is in line with other studies investigating general vaccine attitudes $(31,59,60)$. Compared to our participants' previous actions and behaviors, where the majority had received both childhood and travel vaccinations, the COVID-19 vaccine apparently challenges the participants' tendency to think and act in certain ways. This means that the individual's usual social network, which will typically structure the individual's attitudes, in the context of COVID-19 vaccination seemed to have less importance. This finding is complementary to studies researching willingness to receive the COVID-19 vaccine $(61,62)$. A global survey of potential acceptance of a COVID-19 vaccine in 19 countries demonstrated differences in acceptance rates ranging from almost 90\% (in China) to less than 55\% (in Russia); respondents reporting higher levels of trust in information from government sources were more likely to accept a vaccine and take their employer's advice to do so (63). This suggests that citizens' acceptance of the COVID-19 vaccine in a society is based on trust in the state and authorities more than on trust in opinions in the close social environment.

Our findings illuminate how the participants' health habitus was found to be challenged by the COVID-19 vaccination. The learned dispositions to act in certain ways were for many of the participants that the healthy body and the responsibility to keep the body healthy was an individual matter. In this context, two preconditions for one's own health were particularly dominant: respectively to optimize the body using well-known health advice, and the assumption that the body should be treated naturally. For these participants, the starting point was the individual's position and worldview, where vaccination does not necessarily have direct relevance. The Strategic Advisory Group of Experts, a working group under the World Health Organization, highlight three drivers of vaccine hesitancy: complacency, convenience, and confidence (64). Complacency concerns citizens' perceptions of the risk of contracting vaccinepreventable diseases and therefore their perceptions of the necessity of obtaining vaccination, whereas convenience is based on socioeconomic factors such as availability, accessibility, affordability, and low health literacy. Low confidence stems from a lack of trust in various aspects of health care, such as the vaccine itself, healthcare professionals administering vaccines, or policymakers who advocate for vaccination. These vaccine hesitancy issues have been confirmed in other research as well, indicating that this hesitancy poses dangers to both the individual and their community, if they do not get vaccinated $(65,66)$. Our study complementarily also illuminated how recommendations for COVID-19 vaccination challenge the participants' habitus in that they were forced to revisit their own incorporated assumptions and attitudes. For some of these participants, vaccination against COVID-19 had no meaning and value at an individual level and they perceived vaccination as being made sick. On the other hand, our study findings also point at a collective responsibility expressed by the participants. What is at stake for these individuals is that if all or most citizens are vaccinated, then you can get together with family and friends again as well as embrace a long-missed everyday life again. In this context, habitus becomes a structuring intermediary between the individual and the outside world, whereby it is seen that objective structures such as community and dependence on each other are internalized in the habitus of 
these participants. A study by Lin et al. (55) reported that the majority of participants would only take the vaccine if it was taken by many in the public, which is supported by another study concluding that willingness to take the vaccine is closely bound to recognition of the vaccine's collective importance (67). This points to a dilemma if the citizens want the community, but at the same time only want the community if the others want too. The question thus becomes how one as a society and fellow human being can count on others acting for the good of the community and thereby try to control a seemingly uncontrollable virus.

For many participants in our study, vaccinations are generally considered as a means of protecting health and thus as an established part of one's matrix of perceptions. This habitus is also challenged by COVID19 vaccination, where some participants perceive this vaccination and possible side effects as dangerous even though they have previously received vaccinations without adverse events. In addition, a combination of lack of knowledge and experience with the newly developed COVID-19 vaccine can lead to uncertainty and insecurity, which is why the individual may be reluctant to receive it. Thus, a discrepancy arises between habitual implicit actions and attitudes towards previous vaccinations, where COVID-19 vaccination brings to light the body's embodied health messages in an uncontrollable way. In relation to COVID-19 vaccination, research indicates that sociodemographic factors do not explain vaccine hesitancy to any helpful degree (67). The discrepancy rather seems related to the COVID-19 vaccine being new $(2,24,67)$ and simultaneously research suggests that the current modes of thinking and communicating about the vaccine fall within too narrow and too clinically oriented of an idea about health, disease, and how complex the human responses to them truly are $(68,69)$.

Our findings further illuminated how unequal dispositions and conditions for acquisition of knowledge affect the collection of health capital and the individual's preconditions for being able to position oneself. In general, participants seek out and select knowledge based on motives that have to do with meeting needs or habits; knowledge that often confirms own attitudes, while others seek out nuanced knowledge that can expand their attitudes. For both groups this collection of knowledge and taking a stand on vaccination is about the collection of health capital; a deeply socialized way of being that positions the individual in relation to others, which applies regardless of whether one says yes or no to vaccination. It means something to the participants to be 'well prepared' in terms of knowledge, and from where they get their knowledge is of great importance for controlling their personal situation. The selected news sources provide social security in that others can acknowledge precisely that type of capital and recognize its value. As a citizen, there are expectations of the state or, more specifically, the health authorities that they take the responsibility of explaining to the population what vaccination entails and what is known about safety and insecurity. However, a paradox is seen in this context among the participants, for whom the opportunity to assess knowledge about vaccination is often related to their own collection of experience as well as that of 'close experts', who are considered more trustworthy than just the information provided by the state. Those who have the capital, in the form of expert opinions and knowledge from highly educated people in their close social network, thus receive support from a collective capital, while other participants in our study point out that they lack the right to express and act in relation to different approaches to knowledge. Complementing the above findings, a study demonstrated that respondents 
who reported higher levels of trust in information from government sources were more likely to accept a COVID-19 vaccine (63), while another study found that a majority of participants would only choose to receive the COVID-19 vaccine if given adequate information (55). Trust in the state and information from the state thus seems important for citizens' decisions about vaccination. To achieve the highest level of compliance, information must be differentiated so that it is targeted at both citizens who obtain mainstream knowledge and citizens who obtain knowledge from research and medical experts. At the same time, citizens who are skeptical must also be considered in order to control what might seem uncontrollable.

For many participants in our study, knowledge is most often obtained in the form of one-way communication such as information directed from the state to the citizen. However, when dialogue and involvement are lacking in this context, this information can be experienced as being controlled by the state at a distance. In this way, the state may reproduce inequalities. A systematic review and metaanalysis of intended uptake and refusal of COVID-19 vaccines concluded that being a woman, younger, with lower income or level of education or affiliation with an ethnic minority group was consistently associated with being less likely to intend to get vaccinated (70). In order to counter these unequal reproductions, dialogue and involvement with citizens are necessary. In addition, Harrison and Wu (68) point out that precisely across a diverse public, constructions of care and social solidarity must be as strong as the desire to protect and determine one's individual health. Thus, society must practice such constructions in words as well as in actions. This probably means a re-imagining of cultures for public health, where the ideal of social solidarity is given enough power to instill and change current guiding ethical constructions.

\section{Study strengths and limitations}

The quality of any empirical study, including case studies, depends on validity, i.e. internal validity, external validity, and reliability (36). Strategies were employed in this study to ensure internal validity, including the collection of in-depth data, prolonged involvement with the data, and use of the participants' own words to illustrate themes (46). All authors performed all stages of the data analysis and interpretation in a reflexive and dialogical process. The strength of this approach was that all authors participated with their individual preconceptions and horizons of understanding, forcing the research team to move back and forth between the parts and the whole in an interpretive spiral (47). It is recommended that interviewers should use eye contact and a confident manner to set the tone for the interview and help establish rapport with the respondent (36). We did, however, conduct the interviews by telephone to prevent the spread of the virus, which might be a limitation to the study's internal validity. Despite this, we experienced that participants appreciated talking about their experiences of and attitudes towards COVID-19 vaccination.

According to Yin, any case study findings are likely to be more convincing and accurate if the case study is based on several different sources of information, because multiple sources of evidence allow for data triangulation and the development of converging lines of inquiry (45). In the present study, however, we

Page 28/36 
did not draw on different methods in the collection of data, which might be a limitation in relation to the external validity and thereby the transferability of the study findings. To strengthen credibility and enable a movement from individual participants' attitudes toward COVID-19 vaccination to a more universal perspective in a society, we drew on Bourdieu's theory in an abductive process (44). This enables a level of transferability of the results of the case despite the mentioned methodological limitations $(43,46)$.

A strategy we took to ensure the best possible reliability (36) of our qualitative case study involved the creation of a case study protocol, which helped standardize the investigation. The protocol included an overview of the project, procedures for the recruitment of participants and data collection, guiding questions, and a plan for analysis, all of which are presented in this paper in order to ensure transparency for the reader. A main strength of our case study is its qualitative approach to the investigation of how the attitudes and beliefs of Danish citizens regarding the offer of a COVID-19 vaccine from the Danish healthcare system are expressed in order to make us wiser as to why people have the attitudes to the vaccination program they have. Indeed, most studies dealing with attitudes assume that external, observable dimensions are related to an internal, underlying variable, and such studies find a 'usually good' correlation between behavioral intent and actual action (71). Complementing these studies, our study contributes with a deeper analysis of factors that co-determine the attitudes of individuals.

Bourdieu's theoretical lens of structures, habitus and capital contributed significantly to shedding light on how attitudes are formed externally and are relatively autonomous from and more than the sum of the individual.

\section{Conclusion}

The state plays a dominant role in structuring citizens' beliefs, attitudes, and actions whether COVID-19 vaccination is perceived by citizens as good or bad. In this context the matter of whether citizens feel included in or excluded by the logic of the state is especially important. A belief in vaccination as a way out of the pandemic is seen in citizens who share the basic truth of the state, while those who hold attitudes against vaccination are excluded from community and society. The consequences of this mean that the state's defining norms for health and epidemic control are perceived as voluntary coercions and veiled common interest, which challenges the trust between state and citizen. Citizens' usual structuring social network seems to have less importance with regard to attitudes towards COVID-19 vaccination.

Citizens' habitus is challenged by the COVID-19 vaccination, and they are forced to revisit their own incorporated assumptions and attitudes. For some individuals, vaccination against COVID-19 is of no meaning and they perceive vaccination as being made sick, while others highlight a collective responsibility to get vaccinated. A combination of lack of knowledge and experience with the newly developed COVID-19 vaccine can lead to uncertainty and insecurity, which is why the individual may be reluctant. Thus, a discrepancy arises with regard to habitual implicit actions and attitudes towards previous vaccinations, where the COVID-19 vaccination brings to light the body's embodied health messages. In this context, habitus may become a structuring intermediary between the individual and the 
outside world, whereby objective structures such as community and dependence on each other may be internalized in habitus.

Citizens have unequal dispositions and conditions for the acquisition of knowledge. Those who have the capital, in the form of expert opinions and knowledge from highly educated people in their close social network, receive support from a collective capital, while other citizens might lack the right to have, express and act in relation to different approaches to knowledge. Often knowledge is delivered in the form of oneway communication, such as information directed from the state to the citizen. When dialogue and involvement are lacking in this context, this communication can be experienced as being controlled by the state at a distance. In this way, the state may reproduce inequalities. Society must though practice such information in words as well as action.

\section{Relevance to Clinical Practice}

We are only just in early winter, and it already looks like we are facing another tough corona winter. Many are vaccinated in Denmark, and the part of the adult population that is not vaccinated is small but large enough that if they are all infected during the winter it could be extremely serious; both for individuals who become ill and die, but also for the healthcare system and thus for the whole population. The overall immediate implications of our research are the potential importance of emphasizing the social benefits of a COVID-19 vaccine in public health messages, as well as the need to be transparent about vaccine safety and efficacy. Public health communications need to be closely aligned to different kinds of collective and individual identities in a dialogical and involving way, including a focus on the individual's health habitus and health capital, in order to respond to social motives. In this way, such announcements may not only help to consolidate the majority who are willing to be vaccinated against COVID-19 but may also increase the will to be vaccinated of those who are hesitant.

\section{Abbreviations}

COVID-19: Coronavirus disease 2019.

\section{Declarations}

\section{Ethics approval and consent to participate:}

Registration and permission were received from the authorities in the Danish Data Protection Agency under the Capital Region of Denmark: (P-2020-276) and the study was undertaken in accordance with the guidelines of the Danish Ethics Research Committee. The participants received verbal and written information about the study prior to the study. Written consent was obtained from the participants. Given the qualitative nature of the study, the local ethics committee in the Capital Region of Denmark ruled that no formal ethical approval was required in this particular case.

\section{Consent for publication:}


Not applicable.

\section{Availability of data and material:}

All authors have full control of all primary raw data (interview transcripts) and will allow the journal to review our data if requested. All raw data are written in Danish. Data are stored in a locked file cabinet in a locked room at the Copenhagen University Hospital as requested by the Danish Data Protection Agency. The data material used in this study is available from the corresponding author on reasonable request which will not conflict with the anonymity and confidentiality of the data.

\section{Competing interests:}

The authors have no conflicts of interest to declare.

\section{Funding:}

This work was supported by the Novo Nordisk Foundation (grant number NNF20SA0062831), and the Heart Center, Rigshospitalet, Copenhagen University Hospital, Denmark.

\section{Acknowledgements:}

The research team wishes to thank all the people who collaborated and participated in this study by sharing their experiences. Without them, this study would not have been possible. We also thank Cecilie Bech Hammer and Thyra Kappel Skau for their help with organizing participants and interview scheduling and with the transcription of the interviews.

\section{Author contributions:}

All authors conceived and contributed to the design and conduct of the study. SKB, CB, IEH and MM conducted the collection of data material and were all involved in the analysis and the writing of the manuscript. MM prepared and completed the drafting of the manuscript, and all authors read and approved the manuscript.

\section{References}

1. Leng A, Maitland E, Wang S, Nicholas S, Liu R, Wang J. Individual preferences for COVID-19 vaccination in China. Vaccine. 2021;39(2).

2. Chou WYS, Budenz A. Considering Emotion in COVID-19 Vaccine Communication: Addressing Vaccine Hesitancy and Fostering Vaccine Confidence. Health Commun. 2020;35(14).

3. LaCour M, Davis T. Vaccine skepticism reflects basic cognitive differences in mortality-related event frequency estimation. Vaccine. 2020;38(21).

4. Sohrabi C, Alsafi Z, O'neill N, Khan M, Kerwan A, Al-Jabir A, et al. World Health Organization declares global emergency: A review of the 2019 novel coronavirus (COVID-19). Int J Surg. 2020;76:71-6. 
5. Łaszewska A, Helter T, Simon J. Perceptions of Covid-19 lockdowns and related public health measures in Austria: a longitudinal online survey. BMC Public Health. 2021;21(1).

6. Pascarella G, Strumia A, Piliego C, Bruno F, Del Buono R, Costa F, et al. COVID-19 diagnosis and management: a comprehensive review. J Intern Med. 2020 May 13;joim.13091.

7. Missel M, Bernild C, Dagyaran I, Christensen SW, Berg SK. A stoic and altruistic orientation towards their work: a qualitative study of healthcare professionals' experiences of awaiting a COVID-19 test result. BMC Health Serv Res. 2020;20(1):1031.

8. Shoja E, Aghamohammadi V, Bazyar H, Moghaddam HR, Nasiri K, Dashti M, et al. Covid-19 effects on the workload of Iranian healthcare workers. BMC Public Health. 2020;20(1).

9. De Kock JH, Latham HA, Leslie SJ, Grindle M, Munoz SA, Ellis L, et al. A rapid review of the impact of COVID-19 on the mental health of healthcare workers: implications for supporting psychological wellbeing. BMC Public Health. 2021;21(1).

10. Baldwin R, Weder B, Mauro D. Economics in the Time of COVID-19. London, UK: Centre for Economic Policy Research; 2020.

11. Lima CK, de Oliveira Nunes JV. The emotional impact of Coronavirus 2019-nCoV (new Coronavirus disease). Psychiatry Res. 2020 Mar 12;287.

12. Guan W, Ni Z, Hu Y, Liang W, Ou C, He J, et al. Clinical characteristics of coronavirus disease 2019 in China. N Engl J Med. 2020;382(18):1808-1720.

13. Moreno C, Wykes T, Galderisi S, Nordentoft M, Crossley N, Jones N, et al. How mental health care should change as a consequence of the COVID-19 pandemic. The Lancet Psychiatry. 2020;7(9):813824.

14. Missel M, Bernild C, Christensen SW, Dagyaran I, Berg SK. It's Not Just a Virus! Lived Experiences of People Diagnosed With COVID-19 Infection in Denmark. Qual Health Res. 2021;31(5):822-834.

15. Missel M, Bernild C, Westh Christensen S, Dagyaran I, Kikkenborg Berg S. The marked body - a qualitative study on survivors embodied experiences of a COVID-19 illness trajectory. Scand J Caring Sci. 2021;March 18.

16. Oakman J, Kinsman N, Stuckey R, Graham M, Weale V. A rapid review of mental and physical health effects of working at home: how do we optimise health? BMC Public Health. 2020;20(1).

17. World Health Organization. WHO Coronavirus (COVID-19) overview. https://covid19.who.int/. 2021.

18. Hodgson SH, Mansatta K, Mallett G, Harris V, Emary KRW, Pollard AJ. What defines an efficacious COVID-19 vaccine? A review of the challenges assessing the clinical efficacy of vaccines against SARS-CoV-2. The Lancet Infectious Diseases. 2021;21(2):e26-e35.

19. Weinberg GA, Szilagyi PG. Vaccine epidemiology: Efficacy, effectiveness, and the translational research roadmap. Journal of Infectious Diseases. 2010;201(11):1607-10.

20. World Health Organization. Draft landscape and tracker of COVID-19 candidate vaccines [Internet]. 2021 [cited 2021 Apr 30]. Available from: https://www.who.int/publications/m/item/draft-landscapeof-covid-19-candidate-vaccines 
21. Ashton J. COVID-19 and the anti-vaxxers. Journal of the Royal Society of Medicine. 2021;114(1):4243.

22. Neumann-Böhme S, Varghese NE, Sabat I, Barros PP, Brouwer W, van Exel J, et al. Once we have it, will we use it? A European survey on willingness to be vaccinated against COVID-19. European Journal of Health Economics. 2020;21(7):977-982.

23. Gørtz M, Brewer NT, Hansen PR, Ejrnæs M. The contagious nature of a vaccine scare: How the introduction of HPV vaccination lifted and eroded MMR vaccination in Denmark. Vaccine. 2020;38(28).

24. Su Z, Wen J, Abbas J, McDonnell D, Cheshmehzangi A, Li X, et al. A race for a better understanding of COVID-19 vaccine non-adopters. Brain, Behav Immun - Heal. 2020;9.

25. Covid-19 Vaccinedashboard [Internet]. [cited 2021 Dec 7]. Available from: https://experience.arcgis.com/experience/9824b03b114244348ef0b10f69f490b4/page/page_3/

26. Danish Health Authority. Vaccination mod COVID-19: Statusrapport (Vaccination against COVID-19: Status report) [Internet]. [cited 2021 Apr 30]. Available from: https://www.sst.dk/-/media/Udgivelser/2021/Corona/Vaccination/Statusrapport/Statusrapportvaccinationsindsats-29_-april.ashx? $\mathrm{la}=$ da\&hash=48BFABDBE1199099C95C64C78BF5FC249DB3CF0C

27. PwC. Danskernes tillid til sundhedssystemet ligger rekordhøj (The Danes' confidence in the health system is at a high record ) [Internet]. 2020 [cited 2021 Apr 30]. Available from: https://www.pwc.dk/da/presse/meddelelser/2020/danskernes-tillid-til-sundhedssystemet-liggerrekordhoej.html

28. Med D, Sønderskov KM, Dinesen PT, Dinesen Østergaard S. Sustained COVID-19 vaccine willingness after safety concerns over the Oxford-AstraZeneca vaccine. Danish Med J . 2021;68(5):3210292.

29. Sjøgren K. Danskerne er klar til at lade sig coronavaccinere (Danes are ready for being vaccinated against corona virus) [Internet]. Aarhus; 2020 Oct [cited 2021 Apr 30]. Available from: https://dagensmedicin.dk/stor-undersoegelse-danskerne-er-klar-til-at-lade-sig-coronavaccinere/

30. Rozbroj T, Lyons A, Lucke J. Understanding how the Australian vaccine-refusal movement perceives itself. Heal Soc Care Community. 2020.

31. Salmon DA, Dudley MZ, Glanz JM, Omer SB. Vaccine hesitancy: Causes, consequences, and a call to action. Vaccine. 2015;33.

32. Poland GA, Jacobson RM, Ovsyannikova IG. Trends affecting the future of vaccine development and delivery: The role of demographics, regulatory science, the anti-vaccine movement, and vaccinomics. Vaccine. 2009;27:25-26.

33. Khurana A, Allawadhi P, Khurana I, Allwadhi S, Weiskirchen R, Banothu AK, et al. Role of nanotechnology behind the success of mRNA vaccines for COVID-19. Nano Today. 2021; Jun;38.

34. Brunson EK. The impact of social networks on parents' vaccination decisions. Pediatrics. 2013;131(5):e1397-404. 
35. Attwell K, Meyer SB, Ward PR. The social basis of vaccine questioning and refusal: A qualitative study employing bourdieu's concepts of "capitals" and "habitus." Int J Environ Res Public Health. 2018;15(5).

36. Baškarada S. Qualitative Case Study Guidelines. Qual Rep. 2014.

37. Bourdieu P. Outline of a theory of practice. Cambridge: Cambridge, U.K.: Cambridge University Press; 1977.

38. Larsen K. Sundhedskapital - investeringer i kroppen [Health capital - investments in the body]. Aalborg: Samfundslitteratur; 2021.

39. Bourdieu P. The logic of practice. Stanford: Stanford University Press; 1990.

40. Bourdieu P \& WLJD. Refleksiv sociologi: mål og midler [An invitation to reflexive sociology]. Silberbrandt H, editor. Copenhagen: Hans Reitzel; 1995.

41. Hallett T, Matthew G. Bourdieu and Organizations: Hidden Traces, Macro Influence, and Micro Potential. In: Jeffery Sallaz and Thomas Medvetz, editor. Oxford Handbook of Pierre Bourdieu. New York, USA: Oxford University Press; 2018. p. 273-98.

42. Prieur A\& SC. Pierre Bourdieu - en introduktion [Pierre Bourdieu - an introduction]. Copenhagen: Hans Reitzel; 2006.

43. Flyvbjerg B. Five Misunderstandings About Case-Study Research. Qual Inq. 2006;12(2):219-45.

44. Polit DF, Beck CT. Nursing research: generating and assessing evidence for nursing practice. 11th ed. Wolters Kluwer; 2020.

45. Yin RK. Case Study Research: Design and Methods. Vol. 5. Los Angeles: SAGE (Applied Social Research Methods); 2009.

46. Eisenhardt KM, Graebner ME. Theory Building from Cases: Opportunities and Challenges. Acad Manag J. 2007;50(1):25-32.

47. Gadamer 1900-2002 H-G. Truth and method. 2., e. Continuum impacts. London: Continuum; 2004.

48. Bourdieu P. The forms of capital. In: Richardson JG, editor. Handbook of Theory and Research for the Sociology of Education. Freenwood Press; 1986. p. 280-91.

49. World Medical Association Declaration of Helsinki. JAMA. 2013 Nov;310(20):2191.

50. Leyton D. Social structure, its epistemological uses, and the construction of the subject in Bourdieu's sociology. Vol. 29, Universum. 2014.

51. Portes A. Social capital: Its origins and applications in modern sociology. Annu Rev Sociol. 1998;24:1-24.

52. Bourdieu P. On the State: Lectures at the Collége de Fdeance 1989-1992. Cambridge: Polity Press; 2014.

53. Bourdieu P, Passeron J-C. Reproduction in Education, Society and Culture. London: Sage Publications; 1990.

54. Danish Health Authority [Internet]. [cited 2021 Oct 30]. Available from: https://www.sst.dk/en/English 
55. Lin Y, Hu Z, Zhao Q, Alias H, Danaee M, Wong LP. Understanding COVID-19 vaccine demand and hesitancy: A nationwide online survey in China. PLoS Negl Trop Dis. 2020;14(12).

56. French J, Deshpande S, Evans W, Obregon R. Key guidelines in developing a pre-emptive COVID-19 vaccination uptake promotion strategy. International Journal of Environmental Research and Public Health. 2020;17(16):5893.

57. Bish A, Yardley L, Nicoll A, Michie S. Factors associated with uptake of vaccination against pandemic influenza: A systematic review. Vaccine. 2011;29(38): 6472-84.

58. Fournet N, Mollema L, Ruijs WL, Harmsen IA, Keck F, Durand JY, et al. Under-vaccinated groups in Europe and their beliefs, attitudes and reasons for non-vaccination; Two systematic reviews. BMC Public Health. 2018;18(1):196.

59. Healy CM, Montesinos DP, Middleman AB. Parent and provider perspectives on immunization: Are providers overestimating parental concerns? Vaccine. 2014;32(5):579-84.

60. Harapan H, Fajar JK, Sasmono RT, Kuch U. Dengue vaccine acceptance and willingness to pay. Hum Vaccines Immunother. 2017;13(4):786-790 .

61. Wong MCS, Wong ELY, Huang J, Cheung AWL, Law K, Chong MKC, et al. Acceptance of the COVID-19 vaccine based on the health belief model: A population-based survey in Hong Kong. Vaccine. 2021;39(7).

62. Wake AD. The willingness to receive covid-19 vaccine and its associated factors: "vaccination refusal could prolong the war of this pandemic" - a systematic review. Risk Management and Healthcare Policy. 2021;14:2609-2623.

63. Lazarus J V., Ratzan SC, Palayew A, Gostin LO, Larson HJ, Rabin K, et al. A global survey of potential acceptance of a COVID-19 vaccine. Nat Med. 2021;27(2).

64. MacDonald NE, Eskola J, Liang X, Chaudhuri M, Dube E, Gellin B, et al. Vaccine hesitancy: Definition, scope and determinants. Vaccine. 2015;33(34):4161-4.

65. Coustasse A, Kimble C, Maxik K. COVID-19 and Vaccine Hesitancy: A Challenge the United States Must Overcome. J Ambul Care Manage. 2021;44(1).

66. McAteer J, Yildirim I, Chahroudi A. The VACCINES act: Deciphering vaccine hesitancy in the time of COVID-19. Clinical Infectious Diseases. 2020;71(15):703-705.

67. Freeman D, Loe BS, Chadwick A, Vaccari C, Waite F, Rosebrock L, et al. COVID-19 vaccine hesitancy in the UK: The Oxford coronavirus explanations, attitudes, and narratives survey (Oceans) II. Psychol Med. 2021:1-15.

68. Harrison EA, Wu JW. Vaccine confidence in the time of COVID-19. Eur J Epidemiol. 2020;35(4):325330.

69. Huang F, Ding H, Liu Z, Wu P, Zhu M, Li A, et al. How fear and collectivism influence public's preventive intention towards COVID-19 infection: a study based on big data from the social media. BMC Public Health. 2020;20(1). 
70. Robinson E, Jones A, Lesser I, Daly M. International estimates of intended uptake and refusal of COVID-19 vaccines: A rapid systematic review and meta-analysis of large nationally representative samples. Vaccine. 2021;39(15):2024-2034.

71. Andersson B. Sociologiens brug af begreberne holdning og værdi [Sociology's use of the concepts of attitude and value]. Danish Sociol. 2004;15(4):26-39. 